Wang, J. and Gardner, L. (2017). Flexural buckling of hot-finished high strength steel SHS and RHS columns. Journal of Structural Engineering, ASCE. 143(6), 04017028.

\title{
FLEXURAL BUCKLING OF HOT-FINISHED HIGH STRENGTH STEEL SHS AND RHS COLUMNS
}

\author{
Jie Wang ${ }^{*, 1} \quad$ Leroy Gardner ${ }^{2}$
}

\begin{abstract}
An experimental and numerical study of the flexural buckling behavior of hot-finished high strength steel (HSS) square and rectangular hollow section (SHS and RHS) columns is described in this paper. A total of 30 hot-finished S460 and S690 hollow section column specimens have been tested in compression with pin-ended boundary conditions. Finite element (FE) models have been developed to replicate the experiments, and employed in a subsequent 6 parametric study considering a range of member geometries. Based on the test and FE results, the applicability of the current column design curves in European, North American, Chinese and Australian structural steel design standards to hot-finished HSS SHS and RHS columns has been verified by means of reliability analyses.
\end{abstract}

Keywords: AISC 360, AS 4100, Buckling, Column, Eurocode 3, Experiment, GB 50017, High strength steels, Hot-finished hollow sections, Member instability, Testing, SHS, RHS, Reliability analysis

The development of modern production techniques, such as thermo-mechanical rolling and quenching and tempering, has enabled high strength steels (HSS) with

\footnotetext{
${ }^{1}$ Corresponding author. PhD. Department of Civil and Environmental engineering, Imperial College London, South Kensington, London, UK, SW7 2AZ.Email: jw612@ic.ac.uk.

${ }^{2}$ Professor. Department of Civil and Environmental engineering, Imperial College London, South Kensington, London, UK, SW7 2AZ. Email: leroy.gardner@ic.ac.uk.
} 
yield strengths up to $1100 \mathrm{~N} / \mathrm{mm}^{2}$, while retaining good weldability and adequate toughness and ductility, to be produced (IABSE 2005). Their potential in structural applications has been demonstrated in existing landmark bridges and buildings, such as the Millau Viaduct in France, the Australia Star City in Australia (Pocock 2006) and the NRG Stadium in Houston, USA (Griffis et al. 2003). However, at present, there is limited available structural design guidance. The American structural steel design standard AISC 360-10 (AISC 2010) covers steel grades up to S690 (ASTM A514). The Chinese code GB 50017 (MOHURD 2003) provides design rules for steel grades up to S420. In Australia, the standard AS 4100 (Standards Australia 1998) originally covered steels with yield strengths up to $450 \mathrm{~N} / \mathrm{mm}^{2}$, but a recent amendment AS 4100 AMDT 1-2012 (Standards Australia 2012) extended the scope of application up to $690 \mathrm{~N} / \mathrm{mm}^{2}$. In each of these codes, high strength steels are essentially treated in the same way as conventional strength steels. In Europe, EN 1993-1-12 (CEN 2007) was published specifically for the structural design of high strength steels (S460-S700), but is again, essentially, a simple extension of the conventional carbon steel design rules provided in EN 1993-1-1 (CEN 2005).

The aim of the current study is to contribute towards the development of accurate design rules for hot-finished HSS columns. Previous work on HSS columns include experimental studies by Rasmussen and Hancock (1995) on S690 welded box- and Isection columns and a number of more recent studies on welded HSS columns in steel grades S460 (Ban et al. 2012; Wang et al. 2012, 2014), S690 (Shi et al. 2012), and S960 (Shi et al. 2012; Ban et al. 2013). In these studies, it was generally concluded that HSS columns possess higher normalized buckling resistances than their conventional carbon steel counterparts, which can be attributed to the reduced sensitivity of HSS members to geometric imperfections and lower residual stresses in HSS sections as a proportion of the yield strength (IABSE 2005).

Since previous studies have mainly focused on welded sections, this paper de- 
scribes a series of experiments on hot-finished S460 and S690 tubular members. Rigorous finite element (FE) models are developed and validated against the test results, and subsequently employed to generate parametric results. Based on the test and FE results, statistical reliability analyses are performed to assess the applicability of the EC 3 (CEN 2005; 2007) HSS column design curve, and also those in North American (AISC 2010), Chinese (MOHURD 2003) and Australian (Standards Australia 1998) conventional carbon steel design standard, on hot-finished HSS tubular members.

\section{EXPERIMENTAL STUDY}

A comprehensive testing programme on hot-finished S460NH and S690QH square and rectangular hollow section (SHS and RHS) elements has been carried out. The experiments were designed to cover different structural aspects at material level (Wang et al. 2017), cross-section level (Wang et al. 2016, 2017; Gkantou et al. 2016) and member level. Focusing on the member behavior, this paper describes a series of tests on SHS columns; RHS columns are studied numerically, as detailed later in this paper. The test specimens comprised five cross-section sizes: S460 SHS $50 \times 50 \times 5$, $70 \times 70 \times 6.3$ and $100 \times 100 \times 5$, and S690 SHS $50 \times 50 \times 5$ and $100 \times 100 \times 5.6$. Although these section sizes are at the smaller end of the commercially available range, the proportions of the test specimens, which is the dominant factor in controlling their buckling response, were representative of typical compression members found in practice and no significant influence from size effects would be anticipated. The S460NH and S690QH sections were hot-rolled from continuously cast round ingots which were then hollowed out in a piercing mill to the final section shape. The S460NH sections were subsequently normalised, while the S690QH sections were quenched and tempered. For both materials, the resulting sections are categorised as hot-finished seamless tubes. Tensile material coupon tests were performed on all material. 


\section{Tensile Coupon Tests}

To determine the engineering stress-strain response of the material, tensile coupons extracted from both the flat and corner regions of each cross-section were tested in accordance with EN ISO 6892-1 (CEN 2009). The detailed testing procedure has been described by Wang et al. (2017), while a summary of the flat (F) and corner (C) coupon test results is given herein in Table 2, where $E$ is the material Young's modulus, $f_{\mathrm{y}}$ is the (upper) yield strength, $f_{\mathrm{u}}$ is the ultimate tensile strength, and $\varepsilon_{\mathrm{f}}$ is the plastic strain at fracture, calculated based on the elongation over the standard gauge length $5.65 \sqrt{A_{\mathrm{c}}}, A_{\mathrm{c}}$ being the cross-sectional area of the coupon (CEN 2009). Typical measured stress-strain curves are plotted in Fig. 1, showing the S460 SHS $50 \times 50 \times 5$ and S690 SHS $50 \times 50 \times 5$ coupon results. Both steel grades display the anticipated sharply defined yield point, yield plateau and subsequent strain hardening, as expected for hotfinished materials, while the S690 materials present less strain hardening (indicated by lower $f_{\mathrm{u}} / f_{\mathrm{y}}$ ratios) and lower ductility $\left(\varepsilon_{\mathrm{f}}\right)$ than the $\mathrm{S} 460$ coupons, as can be seen in Table 2 and Fig. 1. Given the observed similarity between the flat and corner material, representative mean values of the flat coupon results, as summarized in Table 1, were adopted for each cross-section in the subsequent member test result analysis and numerical modeling.

\section{Residual stress measurements}

The existence of residual stresses in structural elements can cause premature yielding, loss of stiffness and hence a reduction in load carrying capacity. Knowledge of the residual stress distribution within steel cross-sections is therefore crucial. As part of the present study, measurements of residual stresses in a hot-finished S690 SHS $90 \times 90 \times 5.6$ specimen were made using the sectioning method, as detailed in Wang et al. (2016). It was observed that no significant through-thickness bending residual stresses existed, and that the axial membrane residual stresses were also low, with 
maximum magnitudes of $0.055 \mathrm{f}_{\mathrm{y}}$ in tension and $0.031 \mathrm{f}_{\mathrm{y}}$ in compression, as shown in Fig. 2. Based on the obtained results, a residual stress distribution model for hotfinished high strength steel SHS and RHS was developed, as given in Figure 3. This residual stress pattern was introduced into the numerical models for the FE validation study, as described later.

\section{Flexural buckling tests}

To investigate the flexural buckling response of HSS tubular members, a total of 30 column specimens were tested. Five cross-section sizes with varying lengths enabled a wide spectrum of member slenderness (0.35-2.22) to be studied. A list of the specimens, together with their designations and measured geometric dimensions, is provided in Table 3, where $h, b, t$ and $r_{\mathrm{i}}$ are the depth, width, wall thickness and inner radius of the corner region of the cross-sections, respectively, as indicated in Fig. 6, $L_{\mathrm{cr}}$ is the effective buckling length of the specimens, $\omega_{\mathrm{i}}$ is the global imperfection amplitude derived from strain gauge readings following the procedure described later in this section, and $\bar{\lambda}$ is the relative member slenderness as defined in EN 1993-1-1 (CEN 2005).

All the tests were performed using an Intron $2000 \mathrm{kN}$ machine; the set-up is illustrated in Figs. 4 and 5 and is similar to that employed by Afshan and Gardner (2013) and Chan and Gardner (2009). Pin-ended boundary conditions were achieved through the use of hardened steel knife edge supports, allowing only in-plane rotation about one-axis (i.e. the axis of buckling, as shown in Fig. 6). The distance between the top and bottom knife edges was taken as the specimen buckling length, $L_{\mathrm{cr}}$, which was equal to the member cut-length plus $75 \mathrm{~mm}$ at each end, as shown in Fig. 4. The specimens were loaded under displacement control at a loading rate of $L_{\mathrm{cr}} / 2000$ per min. The monitored variables during the test included the applied axial load, the endshortening, the longitudinal strains and the lateral deflection at the mid-height of the 
member. The axial load and displacement were obtained form the loading rig directly. The longitudinal strains were measured by four linear electrical resistance strain gauges fixed at the mid-length of the member in the arrangement shown in Fig. 6. The lateral deflection at mid-height was recorded through the use of a linear variable differential transformer (LVDT). Readings of all the monitored variables and input voltage were recorded at $1 \mathrm{~s}$ intervals using the data acquisition equipment DATASCAN and logged using the DSLOG software.

The global imperfection amplitude, $\omega_{i}$, consisting of both member bow imperfection and load eccentricity, can be calculated from the strain gauge readings using Eq. 1 (Gkantou et al. 2016), where $\psi$ is the ratio between the strains on the convex and concave sides of the cross-section, $\omega$ is the 2 nd-order eccentricity (i.e. the lateral deflection) recorded by the LVDT at mid-height, and $I, A$ and $h$ are the second moment of area, cross-sectional area and depth of the specimens, respectively. Prior to testing, the effective imperfection (out-of-straightness plus load eccentricity) in all specimens was adjusted to achieve as close as possible to $L_{\mathrm{cr}} / 1000$ by means of two eccentricity adjusting devices positioned at each end of the members, as shown in Fig. 5. Local (plate) geometric imperfections were not considered in the current study owing to the relatively stocky geometries of the cross-sections that are insensitive to local buckling.

$$
\omega_{\mathrm{i}}=\frac{2 I(1-\psi)}{A h(1+\psi)}-\omega
$$

All the specimens exhibited a global buckling failure mode as displayed in Fig. 5. The achieved ultimate load, $N_{\mathrm{u}}$, in each member is reported in Table 3 . The loaddeformation relationships obtained from the tests are shown in Figs. 7 - 10, where the vertical axis is the applied axial load and the horizontal axis is the lateral deflection recorded by the LVDT at mid-height, $\omega$. 


\section{Load-lateral deflection response of HSS columns}

The load-lateral deflection curves of the tested specimens can be assessed in relation to the theoretical response as governed by the elastic buckling load $N_{\mathrm{cr}}$, the yield load $N_{\mathrm{y}}$, the second order elastic behavior and the second order rigid plastic behavior. To illustrate this, examples are given in Figs. 11a and 11b, showing the test results of the C1L1 and C1L6 members, respectively, plotted with the corresponding theoretical models, which are described as followed. In relatively slender members (e.g. the C1L6 member shown in Fig. 11b), elastic buckling tends to govern the member failure, whereas the resistance of stockier members (e.g. the C1L3 member in Fig. 11a) is dominated by yielding.

The second order elastic and second order rigid plastic models can be used to trace the load-displacement equilibrium path of a compressive member. The second order elastic curve describes the load-lateral deflection response of a compressive member with an assumed initial sinusoidal imperfection, and can be expressed using Eq. 2. In Figs. $11 \mathrm{a}$ and $11 \mathrm{~b}$, the second order elastic paths were plotted based on the measured imperfections.

$$
N=N_{\text {cr }}\left(\frac{\omega}{\omega+\omega_{\mathrm{i}}}\right)
$$

The second order rigid plastic model assumes that a plastic hinge is formed at the mid-height of the member, as shown in Fig. 12. Under such deformation, the hinge will resist both the compressive force $N$ and the second order bending moment $N\left(\omega+\omega_{\mathrm{i}}\right)$ at mid-height. By assuming a full plastic stress distribution across the cross-section, as illustrated in Fig. 13, where the compression is resisted by the central region (C2) while the moment is taken by the two outer regions ( $\mathrm{C} 1$ and $\mathrm{T} 3)$, a relationship between the mid-height deflection and the applied compressive force can be established. As can be seen in Figs. 11a and 11b, the test results are very well captured by the envelope 
of the two second order boundaries, with the second order elastic model fitting the initial elastic response of the test specimens and the post-ultimate path merging into the second order rigid plastic curve. Similar agreement was also achieved for the other tested specimens. The column test results are employed in the validation of numerical models in the next section.

\section{NUMERICAL STUDY}

\section{Modeling assumptions}

Numerical modeling was carried out firstly to replicate the experimental results, and subsequently to generate parametric results. The finite element analysis package ABAQUS (2014) was employed throughout the study. A fine mesh of threedimensional four-noded, reduced integration shell element (S4R) was adopted for all the models. The flat parts of the cross-sections had an element size of the wall thickness $t$ and the corner regions were meshed with a constant number of 5 elements.

The measured material and geometric properties were incorporated into the numerical models for the validation study. Given that no significant difference was observed in the stress-strain responses of the flat and corner material, the average flat coupon test results, as reported in Table 1, were employed in the FE models. For shell elements, ABAQUS requires the measured engineering stress-strain curve to be transferred into true stress-log plastic strain before inputting into the model. The true stress, $\sigma_{\text {true }}$, and logarithmic plastic strain, $\varepsilon_{\ln }^{\mathrm{pl}}$, can be obtained using Eqs. 3 and 4, respectively, where $E$ is the Young's modulus, $\sigma_{\text {nom }}$ is the engineering stress and $\varepsilon_{\text {nom }}$ is the engineering strain.

$$
\begin{gathered}
\sigma_{\text {true }}=\sigma_{\text {nom }}\left(1+\varepsilon_{\text {nom }}\right) \\
\varepsilon_{\text {ln }}^{\mathrm{pl}}=\ln \left(1+\varepsilon_{\text {nom }}\right)-\frac{\sigma_{\text {nom }}}{E}
\end{gathered}
$$


The pin-ended boundary conditions employed in the tests were replicated in the numerical models, and each model was assigned an initial geometric imperfection in the form of the first global eigenmode with the amplitude reported in Table 3. The residual stress pattern illustrated in Fig.3, developed based on the measured residual stress amplitudes (Fig. 2), was also applied to the models. Owing to their low magnitudes, models without residual stresses were also simulated to assess their influence. Considering both geometrical and material nonlinearities, the FE models were solved by means of the modified Riks method (ABAQUS 2014), allowing the pre- and postultimate behavior of the columns to be traced.

\section{Validation of FE models}

The ability of the numerical models to capture accurately the behavior observed in the experiments was assessed throughout a series of comparisons between the test and FE results. First, the experimental ultimate loads were compared to those obtained from the numerical models with and without residual stresses, as shown in Table 4. Typical failure modes of the test specimens and FE models are given in Fig. 14, while typical load-lateral deflection curves derived from the FE models (for members C1L5 and C5L3) are plotted against the test results in Figs. 15a and 15b, respectively. As can be seen in Table 4 and from Figs. 15a and 15b, the FE models with and without residual stresses were both able to capture accurately the flexural buckling response of the column specimens, with an average error of $1.5 \%$ and $1.7 \%$, respectively, in the ultimate load predictions. Given the very low magnitude of the residual stresses and their minimal influence on the member strengths, FE models without residual stresses were used in the parametric investigation.

\section{FE parametric studies}

Following successful validation of the FE models, a series of parametric studies were carried out. A total of 144 models were generated, covering two steel grades 
(S460 and S690), two cross-section aspect ratios $(150 \times 150$ and $250 \times 150)$, three crosssection slendernesses (Class 1, 2 and 3 according to the cross-section classification limits given in Eurocode 3 (CEN 2005)), eight column slendernesses (0.45 - 2.5), and two buckling axes (minor and major) for the $250 \times 150$ section sizes. The input material parameters in the S460 and S690 FE models were defined based on the coupon test results of S460 SHS $50 \times 50 \times 5$ and S690 SHS $50 \times 50 \times 5$, respectively. In the nonlinear analyses, geometric imperfections were adopted in the form of the first global eigenmode (approximately a half-sine wave), with an amplitude of $L_{\mathrm{cr}} / 1000$. This imperfection amplitude was employed in the formulation of the European, Chinese and Australian column buckling curves (CEN 2005; MOHURD 2003; Standards Australia 1998), while a smaller value of $L_{\mathrm{cr}} / 1500$ was adopted in the development of the AISC buckling curves (AISC 2010). The generated parametric results are used, in conjunction with the test results, to assess the applicability of different codified buckling curves to the design of hot-finished HSS SHS and RHS columns.

\section{DESIGN RECOMMENDATIONS}

The current column design rules in the European, North American, Chinese and Australian structural steel design codes (CEN 2005; AISC 2010; MOHURD 2003; Standards Australia 1998) are introduced in this section. Based on the obtained test and numerical results, reliability analyses are carried out to examine the suitability of the presented design provisions for hot-finished S460 and S690 SHS and RHS columns.

\section{Current design provisions}

The compressive strength (flexural buckling resistance) of a column, $N_{\mathrm{b}}$, is typically calculated by multiplying the plastic resistance (yield load) of the cross-section, $A f_{\mathrm{y}}$, with a buckling reduction factor, $\chi$, to account for member instability, as shown in Eq. 5. The relationships between this reduction factor and the member slenderness, generally referred to as buckling curves, vary between standards, as described in this 
section. It should be noted that all the cross-sections in this study are classified as "fully effective" in the context of the design codes considered, and the case of slender (Class 4) cross-sections, in which local buckling prevents the attainment of the yield load, is out of the scope of this paper.

$$
N_{\mathrm{b}}=\chi A f_{\mathrm{y}} \quad \text { for fully effective cross-sections }
$$

\section{European Standard (EC 3)}

In Eurocode 3 (CEN 2005), the relative member slenderness, denoted $\bar{\lambda}_{\mathrm{EC}}$ herein, is defined by Eq. 6, where $i$ is the radius of gyration about the relevant axis, and other symbols are as previously defined.

$$
\bar{\lambda}_{\mathrm{EC}}=\sqrt{\frac{A f_{\mathrm{y}}}{N_{\mathrm{cr}}}}=\frac{L_{\mathrm{cr}}}{i \pi} \sqrt{\frac{f_{\mathrm{y}}}{E}}
$$

Eurocode 3 (CEN 2005) employs the multiple column curve concept (Sfintesco 1970; Jacquet 1970; Beer and Schulz 1970) and, using the Ayrton-Perry (Ayrton and Perry 1886) formula, defines a set of five buckling curves through five discrete values of the imperfection factor $\alpha$, as given in Eqs. 7 and 8. It should be noted that in Eq.8, the term $\alpha\left(\bar{\lambda}_{\mathrm{EC}}-0.2\right)$ is the imperfection term $\eta$, which was taken on the basis of first yield as $\eta=h A \omega_{\mathrm{i}} / 2 I$ in the original Ayrton-Perry (Ayrton and Perry 1886) expression, with $h, A, \omega_{\mathrm{i}}$ and $I$ being as previously defined. The buckling curve selection depends on the cross-section shape, buckling axis, steel grade and manufacturing route of the member. For hot-finished S460 SHS and RHS, buckling curve $a_{0}$ with an imperfection factor of 0.13 is specified in EN 1993-1-1 (CEN 2005). For higher steel grades, up to S700, EN 1993-1-12 (CEN 2007) states that the buckling curves for S460 material should be adopted. Comparison between the Eurocode 3 buckling curve $a_{0}$ and the test/FE data of both steel grades is shown in Fig. 16, where the vertical axis for the test/FE data is the ultimate compressive resistance normalized by the cross-sectional 
plastic resistance $A f_{\mathrm{y}}$.

$$
\begin{gathered}
\chi_{\mathrm{EC}}=\frac{1}{\Phi+\sqrt{\Phi^{2}-\bar{\lambda}_{\mathrm{EC}}^{2}}} \\
\Phi=0.5\left[1+\alpha\left(\bar{\lambda}_{\mathrm{EC}}-0.2\right)+\bar{\lambda}_{\mathrm{EC}}^{2}\right]
\end{gathered}
$$

\section{North American Standard (AISC 360)}

In AISC 360 (AISC 2010), the relative member slenderness $\bar{\lambda}_{\mathrm{AISC}}$ is defined as in Eurocode 3, though with slightly different notation, as given by Eq. 9. In AISC 360, $K$ is the effective length factor, with $K L$ equivalent to the member buckling length $L_{\text {cr }}$ in Eurocode 3, while $r$ is symbol adopted for radius of gyration and $F_{\mathrm{y}}$ is the material yield strength.

$$
\bar{\lambda}_{\mathrm{AISC}}=\frac{K L}{\pi r} \sqrt{\frac{F_{\mathrm{y}}}{E}}=\frac{L_{\mathrm{cr}}}{i \pi} \sqrt{\frac{f_{\mathrm{y}}}{E}}
$$

AISC 360 (AISC 2010) adopts a single column curve which was developed from the SSRC (Structural Stability Research Council) column curves (Bjorhovde and Tall 1971; Bjorhovde 1972, 1978; Ziemian 2010). The single column curve consists of two basic expressions for the buckling reduction factor $\chi_{\mathrm{AISC}}-$ an exponential expression (Eq. 10) in the inelastic range accounting for the effect of residual stresses, and a reduced Euler expression (Eq. 11) in the elastic range where the residual stresses are believed to have minimal influence (Tide 1985). The constant terms in the two equations were determined based on the test data and reliability criteria at the time (Tide 1985, 2001; Beedle 1991). The AISC column curve is also plotted in Fig. 16.

$$
\chi_{\mathrm{AISC}}=0.658^{\bar{\lambda}_{\mathrm{AISC}}^{2}} \quad \text { for } \bar{\lambda}_{\mathrm{AISC}} \leqslant 1.5
$$




$$
\chi_{\mathrm{AISC}}=\frac{0.877}{\bar{\lambda}_{\mathrm{AISC}}^{2}} \quad \text { for } \quad \bar{\lambda}_{\mathrm{AISC}}>1.5
$$

\section{Chinese Standard (GB 50017)}

The relative member slenderness in the Chinese code GB 50017 (MOHURD 2003) $\bar{\lambda}_{\mathrm{GB}}$ is defined in the same manner as in EC 3 (CEN 2005) and AISC (AISC 2010), as given by Eq. 12 .

$$
\bar{\lambda}_{\mathrm{GB}}=\frac{L_{\mathrm{cr}}}{i \pi} \sqrt{\frac{f_{\mathrm{y}}}{E}}
$$

In GB 50017 (MOHURD 2003), a set of four buckling curves are employed. These curves were derived based on computational modeling of columns with various crosssection types ( $\mathrm{Li}$ and Xiao 1982; Li et al. 1985), and are described by an Ayrton-Perry formula (Ayrton and Perry 1886; Luo 1989), as given in Eqs. 13 and 14, where the Ayrton-Perry imperfection term $\eta=\alpha_{3} \bar{\lambda}_{G B}+\alpha_{2}-1$, and $\alpha_{1}, \alpha_{2}$ and $\alpha_{3}$ are factors that depend on the selected buckling curve. For steel strengths up to $420 \mathrm{~N} / \mathrm{mm}^{2}$, which is the maximum strength covers by GB 50017, buckling curve $b$ is specified for hot-finished SHS and RHS with $\alpha_{1}=0.65, \alpha_{2}=0.965$ and $\alpha_{3}=0.300$. The results of the reliability analysis presented in the next section shows that, as in the European Standard, a higher buckling curve can be used for high strength material, and curve a with $\alpha_{1}=0.41, \alpha_{2}=0.986$ and $\alpha_{3}=0.152$ is recommended herein for hot-finished HSS SHS and RHS of grade S460 and above.

$$
\chi_{\mathrm{GB}}=1-\alpha_{1} \bar{\lambda}_{\mathrm{GB}}^{2} \quad \text { for } \quad \bar{\lambda}_{\mathrm{GB}} \leqslant 0.215
$$


$\chi_{\mathrm{GB}}=\frac{1}{2 \bar{\lambda}_{\mathrm{GB}}^{2}}\left[\left(\alpha_{2}+\alpha_{3} \bar{\lambda}_{\mathrm{GB}}+\bar{\lambda}_{\mathrm{GB}}^{2}\right)-\sqrt{\left(\alpha_{2}+\alpha_{3} \bar{\lambda}_{\mathrm{GB}}+\bar{\lambda}_{\mathrm{GB}}^{2}\right)^{2}-4 \bar{\lambda}_{\mathrm{GB}}^{2}}\right]$ for $\bar{\lambda}_{\mathrm{GB}}>0.215$

Australian Standard (AS 4100)

The AS 4100 relative member slenderness $\bar{\lambda}_{\mathrm{AS}}$ is equivalent to $\bar{\lambda}_{\mathrm{EC}}$ multiplied by a factor $\pi \sqrt{\mathrm{E} / 250}$, as defined in Eq. 15 (Standards Australia 1998).

$$
\bar{\lambda}_{\mathrm{AS}}=\frac{L_{\mathrm{cr}}}{i} \sqrt{\frac{f_{\mathrm{y}}}{250}}=\frac{L_{\mathrm{cr}}}{i \pi} \sqrt{\frac{f_{\mathrm{y}}}{E}}\left(\pi \sqrt{\frac{E}{350}}\right)
$$

The AS 4100 (Standards Australia 1998) also adopts the multiple column curve concept. A set of five buckling curves developed from the SSRC column curves (Bjorhovde and Tall 1971; Bjorhovde 1972, 1978; Ziemian 2010) are defined in an Ayrton-Perry (Ayrton and Perry 1886) format. The AS 4100 buckling curves are expressed through Eqs. 16-18, where $\alpha_{\mathrm{a}}$ is a slenderness modifier obtained from regression analysis (Rotter 1982), and $\alpha_{\mathrm{b}}$ is an imperfection factor related to the choice of the buckling curve (Trahair and Bradford 1998; Rotter 1982). The imperfection term $\eta$ in the original Ayrton-Perry formula is replaced by $\eta=0.00326\left(\bar{\lambda}_{\mathrm{AS}}+\alpha_{\mathrm{a}} \alpha_{\mathrm{b}}-13.5\right)$ in the AS 4100 expression. The buckling curve with $\alpha_{\mathrm{b}}=-1.0$, which is currently specified for hot-rolled and cold-formed normal strength steel SHS, RHS and CHS, is adopted for comparison with the HSS SHS and RHS column data generated herein. This curve has been plotted in Fig. 16, with the slenderness $\bar{\lambda}_{\mathrm{AS}}$ being divided by $\pi \sqrt{E / 250}$ to maintain consistency with the other codes.

$$
\chi_{\mathrm{AS}}=\xi\left\{1-\sqrt{\left[1-\left(\frac{90}{\xi\left(\bar{\lambda}_{\mathrm{AS}}+\alpha_{a} \alpha_{b}\right)}\right)^{2}\right]}\right\}
$$


where

$$
\alpha_{a}=\frac{2100\left(\bar{\lambda}_{\mathrm{AS}}-13.5\right)}{\bar{\lambda}_{\mathrm{AS}}^{2}-15.3 \bar{\lambda}_{\mathrm{AS}}+2050}
$$

and

$$
\xi=\frac{\left[\left(\bar{\lambda}_{\mathrm{AS}}+\alpha_{\mathrm{a}} \alpha_{\mathrm{b}}\right) / 90\right]^{2}+1+0.00326\left(\bar{\lambda}_{\mathrm{AS}}+\alpha_{\mathrm{a}} \alpha_{\mathrm{b}}-13.5\right)}{2\left[\left(\bar{\lambda}_{\mathrm{AS}}+\alpha_{\mathrm{a}} \alpha_{\mathrm{b}}\right) / 90\right]^{2}}
$$

\section{Reliability analyses and discussion}

From Fig. 16, it may be observed that the EC 3 and AS 4100 buckling curves are nearly identical, while the GB 50017 curve gives slightly lower predictions in the intermediate slenderness range, and the AISC 360 one is the lowest of the four. All four curves converge towards the Euler elastic buckling curve in the slender range.

In each code, partial factors are applied to the nominal column resistance in order to achieve a specified target reliability. This partial factor is denoted as $\gamma_{\mathrm{M} 1}$ in EC 3 with the value set to unity. In AISC 360 and AS 4100, the partial safety factor is represented by $\phi_{\mathrm{c}}$ and $\phi$, respectively, with a value of 0.9 . Note that $\gamma_{\mathrm{M} 1}$ applies to the dominator whereas $\phi_{\mathrm{c}}$ and $\phi$ appear in the numerator. The Chinese standard GB 50017 implicitly incorporates this factor in the definition of the design yield strength $f_{\mathrm{d}}=f_{\text {nom }} / \gamma_{\mathrm{M}}$, where $\gamma_{\mathrm{M}}$ is dependent on the steel grade and thickness of the material. Since a $\gamma_{M}$ value for high strength steel grades is not specified in GB 50017, a value of $\gamma_{M}=1.1$, based on the results obtained for S460 and S690 steels from a recent study Shi et al. (2016), is adopted herein for both steel grades (S460 and S690); this value is also close to those specified in GB 50017 for S235-S420 steels. The factored column design curves are compared with the test and FE data in Fig. 17, where the four design curves tend to provide safe-side predictions for the S690 members, while some of the S460 test data fall below the EC 3 curve. On average, the normalized S690 column test data are about 5\% higher than the S460 data, but with higher scatter. The normalized 
S690 FE data lie about $2 \%$ above the S460 data.

To examine the suitability of the factored design curves, reliability analyses in accordance with EN 1990 (CEN 2002) and AISC 360 (AISC 2010) were carried out. For the Eurocode analysis, the mean to nominal yield strength ratio $f_{\mathrm{y} \text {,mean }} / f_{\mathrm{y} \text {,nom }}=1.135$ (i.e. the material over-strength) and coefficient of variation of the yield strength $V_{\mathrm{f}_{\mathrm{y}}}=$ 0.055 were obtained from a series of coupon tests results collected from steel producers (Wang et al. 2016). The coefficient of variation of the geometric properties $V_{\mathrm{g}}$ was taken as 0.02 (Byfield and Nethercot 1997). In the AISC analysis, the $f_{\mathrm{y}, \text { mean }} / f_{\mathrm{y}, \text { nom }}, V_{\mathrm{f}_{\mathrm{y}}}$ and $V_{\mathrm{g}}$ values derived from lower grade carbon steel test data were used (Bartlette et al. 2003), with values of $1.028,0.058$ and 0.05 , respectively. To add artificial variability to the numerical results, a variability term $V_{\mathrm{FE}}=0.44$, determined by considering the deviation of numerical to experimental results, was incorporated in both analyses, following a similar approach to Davaine (2005) and Bock et al. (2015).

The key parameters and results of the Eurocode and AISC reliability analyses are summarized in Tables 5 and 6, respectively. In the Eurocode analysis (Table 5), $k_{\mathrm{d}, \mathrm{n}}$ is the design fractile factor for $n$ data points of the dataset under consideration (CEN 2002; Afshan et al. 2015); $b$ is the average ratio of experimental to model resistance based on a least squares fit to the test data; $V_{\delta}$ is the coefficient of variation of the test and $\mathrm{FE}$ results relative to the resistance model; $V_{\mathrm{r}}$ is the combined coefficient of variation incorporating both model and basic variable (material and geometry) uncertainties, where the dependence of the basic variables was separated (Afshan et al. 2015), and hence varies between data points, but the average value for each dataset is reported in Tables 5 and 6; $\gamma_{\mathrm{M} 1}$ is the required partial factor, which can be assessed against the EC 3 specified value of 1.0. In the AISC analysis (Table 6), $V_{\mathrm{Q}}$ is the coefficient of variation of the load effects, determined based on an assumed live-to-dead load ratio of 3:1 for hot-rolled sections (AISC 2010); $V_{\mathrm{R}}$ is equivalent to and calculated in the same way as the $V_{\mathrm{r}}$ parameter in the Eurocode analysis; $\beta$ is the reliability index with 
a target value greater than 2.6 required by AISC 360 for member design.

From Table 5, it may be seen that, using curve $a_{0}$, the required values of $\gamma_{\mathrm{M} 1}$ indicated by the statistical analyses are 1.12 and 1.11 for the S460 and S690 material, respectively considering both the test and FE results. Based on the tests only, slightly higher values are obtained. From these results, which accord with those of Charbrolin (2002) determined during the development of EC 3, it may be concluded that a higher value of $\gamma_{\mathrm{M} 1}$ is required in order to meet the Eurocode reliability requirements. A value of $\gamma_{\mathrm{M} 1}=1.1$ (for both normal strength and high strength steels) is recommended herein, and is consistent with the partial factors employed in the North American, Chinese, and Australian codes. The AISC curve is also found to be satisfactory for both steel grades, as shown in Table 6 , where $\beta$ is equal or greater than 2.6 in all cases. The AS 4100 and GB 50017 design curves gave more conservative predictions than Eurocode 3, and hence may be considered to yield acceptable reliability. Overall, it is concluded that the four selected buckling curves from the European, North American, Chinese and Australian codes can be safely applied to the design of hot-finished HSS SHS and RHS columns, and while the S690 columns perform slightly better than the S460 columns, a separate (higher) buckling is not considered to be warranted at this stage.

\section{CONCLUSIONS}

A comprehensive experimental and numerical study into the flexural buckling behavior of hot-finished high strength steel (HSS) SHS and RHS columns has been carried out in this paper. A total of 30 pin-ended columns have been tested, covering both S460 and S690 steels, five SHS cross-section sizes, and eight member slendernesses $(0.45-2.25)$. The effective global imperfection was adjusted to achieve a value of approximately $L_{\mathrm{cr}} / 1000$ in all test specimens. Incorporating the measured material and geometric properties, FE models have been developed, and shown to be able to accu- 
rately replicate the experimental results. Parametric studies considering both SHS and RHS with various member geometries followed, leading to the generation of a total of 144 FE results. The S690 columns showed improved normalized buckling performance over the $\mathrm{S} 460$ columns by about $5 \%$ in the tests and $2 \%$ in the models. Based on the test and numerical results, reliability analyses in accordance with EN 1990 and AISC 360 were carried out, showing that the current HSS column design curves in the European standard (with $\gamma_{\mathrm{M} 1}=1.1$ ), and those selected from the North American, Chinese and Australian standards, are applicable to hot-finished HSS SHS and RHS columns.

\section{ACKNOWLEDGEMENT}

The authors are grateful to Mr. Gordon Herbert for his assistance during the tests. V\& M DEUTSCHLAND GMBH is acknowledged for the supply of the test specimenS.

\section{REFERENCES}

ABAQUS (2014). ABAQUS/Standard user's manual volume IIII and ABAQUS CAE manual. Version 6.14, Hibbitt and Karlsson and Sorensen Inc. ABAQUS. USA: Pawtucket.

Afshan, S., Francis, P., Baddoo, N., and Gardner, L. (2015). "Reliability analysis of structural stainless steel design provisions." J. Constr. Steel Res., 114, 293-304.

Afshan, S. and Gardner, L. (2013). "Experimental study of cold-formed ferritic stainless steel hollow sections." J. Struct. Eng. ASCE, 139(5), 717-728.

AISC (2010). “Specification for structural steel buildings, ANSI/AISC 360-10.” Chicago.

Ayrton, W. E. and Perry, J. (1886). “On struts.” Engineering (London), 62, 464-465. 
Ban, H. Y., Shi, G., Shi, Y. J., and Bradford, M. A. (2013). "Experimental investigation of the overall buckling behaviour of $960 \mathrm{MPa}$ high strength steel columns." J. Constr. Steel Res., 88, 256-266.

Ban, H. Y., Shi, G., Shi, Y. J., and Wang, Y. Q. (2012). “Overall buckling behavior of $460 \mathrm{MPa}$ high strength steel columns: Experimental investigation and design method.” J. Constr. Steel Res., 74, 140-150.

Bartlette, R. M., Dexter, R. J., Graeser, M., Jelinek, J. J., Schmidt, B. J., and Galambos, T. V. (2003). "Updating standard shape material properties database for design and reliability.” Eng. J., 40(1), 2-14.

Beedle, L. S. (1991). Stability of metal structures: A world view. Structural Stability Research Council, Lehigh Univ. Bethlehem, Pa., 2nd edition.

Beer, H. and Schulz, G. (1970). "Bases théoriques des courbes européenes de flambement." Constr. Metallique, 3, 37-57.

Bjorhovde, R. (1972). "Deterministic and probabilistic approaches to the strength of steel columns.” Ph.D. thesis, Lehigh Univ., Bethlehem, Pa.

Bjorhovde, R. (1978). “The safety of steel columns.” J. Struct. Div., 104(3), 463-477.

Bjorhovde, R. and Tall, L. (1971). "Maximum column strength and the multiple column curve concept." Report No. 338.29, Fritz Engineering Laboratory, Lehigh Univ., Bethlehem, Pa.

Bock, M., Mirada, F. X., and Real, E. (2015). "Statistical evaluation of a new resistance model for cold-formed stainless steel cross-sections subjected to web crippling." Int. J. Steel Struct., 15(1), 227-244.

Byfield, M. P. and Nethercot, D. A. (1997). "Material and geometric properties of structural steel for use in design.” Struct. Eng., 75(21), 363-367. 
Chan, T. M. and Gardner, L. (2009). "Flexural buckling of elliptical hollow section columns.” J. Struct. Eng. ASCE, 135(5), 546-557.

Charbrolin, B. (2002). "Partial safety factors for resistance of steel elements to EC 3 and EC 4 - Calibration for various steel products and failure criteria." (EUR 20344 EN).

Davaine, L. (2005). "Formulations de la résistance au lancement d'une âme métallique de pont raidie longitudinalement - Résistance dite de "Patch Loading".” Ph.D. thesis, L'Institut National des Sciences Appliquées de Rennes, France.

European Committee for Standardization (CEN) (2002). "Eurocode: Basis of structural design, EN 1990:2002.” Brussels, Belgium.

European Committee for Standardization (CEN) (2005). "Eurocode 3: Design of steel structures. Part 1-1: General rules and rules for buildings, EN 1993-1-1.” Brussels, Belgium.

European Committee for Standardization (CEN) (2007). "Eurocode 3: Design of steel structures. Part 1-12: Additional rules for the extension of EN 1993 up to steel grades S700, EN 1993-1-12.” Brussels, Belgium.

European Committee for Standardization (CEN) (2009). "Metallic materials - Tensile testing - Part 1: Method of test at room temperature, ISO 6892-1:2009.” Brussels, Belgium.

Gkantou, M., Theofanous, M., Wang, J., Baniotopoulos, C., and Gardner, L. (2016). "Behaviour of high strength steel eccentric stub columns." Structures and Buildings Submitted.

Griffis, G. L., Axmann, G., and Patel, B. V. (2003). "High-strength steel in the 
long-span retractable roof of Reliant stadium.” 2003 NASCC Proc. Baltimore, MD; NASCC

IABSE (2005). Use and application of high-performance steels for steel structures. International Association for Bridge and Structural Engineering (IABSE).

Jacquet, J. (1970). "Essais de flambement et exploitation statistique." Constr. Metallique, 3, 13-36.

Li, K. X. and Xiao, Y. H. (1982). "Ni suan dan yuan chang du fa ji suan dan zhou shi wen shi gang ya gan de lin jie li." J. of Chongqing Jianzhu Univ., 4, 26-45 In Chinese.

Li, K. X., Xiao, Y. H., Nao, X. F., Cui, J., and Zhu, W. (1985). "Column curves for steel compression member." J. of Chongqing Jianzhu Univ., 1, 24-33 In Chinese.

Luo, F. B. (1989). "Xin ding gang jie gou she ji gui fan (GBJ 17-88) nei rong jie shao." Steel Constr., 1, 1-19 In Chinese.

Ministry of Housing and Urban-Rural Development of the People's Republic of China (MOHURD) (2003). “Code for design of steel structures, GB 50017-2003.” Beijing, China. In Chinese.

Pocock, G. (2006). "High strength steel use in Austalia, Japan and the US." Struct. Eng., 84(21), 27-30.

Rasmussen, K. J. R. and Hancock, G. J. (1995). “Test of high strength steel columns.” J. Constr. Steel Res., 34, 27-52.

Rotter, J. M. (1982). "Multiple column curves by modifying factors." J. Struct. Div., 108(7), 1665-1669. 
Sfintesco, D. (1970). "Fondement expérimental des courbes européennes de flambement." Constr. Metallique, 3, 5-12.

Shi, G., Ban, H. Y., and Bijlaard, F. S. K. (2012). "Tests and numerical study of ultrahigh strength steel columns with end restraints." J. Constr. Steel Res., 70, 236-247.

Shi, G., Zhu, X., and Ban, H. Y. (2016). "Material properties and partial factors for resistance of high-strength steels in China.” J. Constr. Steel Res., 121, 65-79.

Standards Australia (1998). “Steel structures, AS 4100.” Homebush, New South Wales, Australia.

Standards Australia (2012). "Steel structures, AS 4100-1998 Amdt 1-2012." Homebush, New South Wales, Australia.

Tide, R. H. R. (1985). "Reasonable column design equations.” Proc., Annual Technical Session of Structural Stability Research Concil, Cleveland, Ohio, 47-55.

Tide, R. H. R. (2001). "A technical note: Derivation of the LRFD column design equations.” Eng. J., 38(3), 137-139.

Trahair, N. S. and Bradford, M. A. (1998). The behaviour and design of steel structures to AS 4100. E \& FN Spon, London, 3rd edition.

Wang, J., Afshan, S., Gkantou, M., Theofanous, M., Baniotopoulos, C., and Gardner, L. (2016). "Flexural behaviour of hot-finished high strength steel square and rectangular hollow sections.” J. Constr. Steel Res., 121, 97-109.

Wang, J., Afshan, S., Schillo, S. N., Theofanous, M., Feldmann, M., and Gardner, L. (2017). "Material properties and compressive local buckling response of high strength steel square and rectangular hollow sections.” Eng. Struct., 297-315. 
Wang, Y. B., Li, G. Q., Chen, S. W., and Sun, F. F. (2012). "Experimental and numerical study on the behaviour of axially compressed high strength steel columns with H-section.” Eng. Struct., 43, 149-159.

Wang, Y. B., Li, G. Q., Chen, S. W., and Sun, F. F. (2014). "Experimental and numerical study on the behavior of axially compressed high strength steel box-columns." Eng. Struct., 58, 79-91.

Ziemian, R. D. (2010). Guide to stability design criteria for metal structures. John Wiley \& Sons, Inc., Hoboken, New Jersey, 5th edition. 
TABLE 1: Average measured flat coupon results for each cross-section size

\begin{tabular}{llllll}
\hline Cross-section & $\begin{array}{l}E \\
\left(\mathrm{~N} / \mathrm{mm}^{2}\right)\end{array}$ & $\begin{array}{l}f_{\mathrm{y}} \\
\left(\mathrm{N} / \mathrm{mm}^{2}\right)\end{array}$ & $\begin{array}{l}f_{\mathrm{u}} \\
\left(\mathrm{N} / \mathrm{mm}^{2}\right)(\%)\end{array}$ & $\begin{array}{c}\varepsilon_{\mathrm{f}} \\
\left(\% / f_{\mathrm{y}}\right.\end{array}$ \\
\hline S460 SHS $50 \times 50 \times 5$ & 211000 & 505 & 620 & 31.0 & 1.23 \\
S460 SHS $70 \times 70 \times 6.3$ & 212000 & 531 & 752 & 26.3 & 1.41 \\
S460 SHS $100 \times 100 \times 5$ & 211000 & 511 & 616 & 29.2 & 1.21 \\
S690 SHS $50 \times 50 \times 5$ & 206000 & 759 & 790 & 21.7 & 1.04 \\
S690 SHS $100 \times 100 \times 5.6$ & 210000 & 782 & 798 & 19.2 & 1.02 \\
\hline
\end{tabular}

TABLE 2: Measured tensile coupon test results

\begin{tabular}{|c|c|c|c|c|c|c|}
\hline Cross-section & Label & $\begin{array}{l}E \\
\left(\mathrm{~N} / \mathrm{mm}^{2}\right)\end{array}$ & $\begin{array}{l}f_{\mathrm{y}} \\
\left(\mathrm{N} / \mathrm{mm}^{2}\right)\end{array}$ & $\begin{array}{l}f_{\mathrm{u}} \\
\left(\mathrm{N} / \mathrm{mm}^{2}\right.\end{array}$ & $\begin{array}{l}\varepsilon_{\mathrm{f}} \\
(\%)\end{array}$ & $f_{\mathrm{u}} / f_{\mathrm{y}}$ \\
\hline \multirow{4}{*}{ S460 SHS $50 \times 50 \times 5$} & F1 & 211000 & 494 & 618 & 31.5 & 1.25 \\
\hline & $\mathrm{F} 2$ & 211000 & 506 & 620 & 30.0 & 1.23 \\
\hline & F3 & 211000 & 515 & 623 & 31.4 & 1.21 \\
\hline & $\mathrm{C}$ & 208000 & 481 & 631 & 26.2 & 1.31 \\
\hline \multirow{4}{*}{ S460 SHS $70 \times 70 \times 6.3$} & F1 & 212000 & 529 & 757 & 26.6 & 1.43 \\
\hline & $\mathrm{F} 2$ & 212000 & 534 & 744 & 27.2 & 1.39 \\
\hline & F3 & 215000 & 542 & 769 & 26.2 & 1.42 \\
\hline & $\mathrm{F} 4$ & 209000 & 520 & 736 & 25.0 & 1.42 \\
\hline \multirow{3}{*}{ S460 SHS $100 \times 100 \times 5$} & F1 & 211000 & 515 & 618 & 30.5 & 1.20 \\
\hline & $\mathrm{F} 2$ & 212000 & 507 & 615 & 27.8 & 1.21 \\
\hline & $\mathrm{C}$ & 208000 & 528 & 636 & 23.3 & 1.20 \\
\hline \multirow{5}{*}{ S690 SHS $50 \times 50 \times 5$} & F1 & 200000 & 749 & 783 & 20.3 & 1.05 \\
\hline & $\mathrm{F} 2$ & 210000 & 776 & 800 & 19.1 & 1.03 \\
\hline & $\mathrm{F} 3$ & 205000 & 761 & 795 & 19.8 & 1.04 \\
\hline & $\mathrm{F} 4$ & 202000 & 750 & 781 & 20.2 & 1.04 \\
\hline & $\mathrm{C}$ & 210000 & 782 & 813 & 19.2 & 1.03 \\
\hline \multirow{3}{*}{ S690 SHS $100 \times 100 \times 5.6$} & F1 & 212000 & 794 & 803 & 20.0 & 1.01 \\
\hline & $\mathrm{F} 2$ & 209000 & 770 & 793 & 18.4 & 1.03 \\
\hline & $\mathrm{C}$ & 209000 & 774 & 792 & 20.2 & 1.02 \\
\hline
\end{tabular}


TABLE 3: Measured geometric dimensions and key test results of column specimens

\begin{tabular}{|c|c|c|c|c|c|c|c|c|c|}
\hline Cross-section & Label & $\begin{array}{l}L_{\mathrm{cr}} \\
(\mathrm{mm})\end{array}$ & $\begin{array}{l}\text { h } \\
(\mathrm{mm})\end{array}$ & $\begin{array}{l}b \\
(\mathrm{~mm})\end{array}$ & $\begin{array}{l}t \\
(\mathrm{~mm})\end{array}$ & $\begin{array}{l}r_{\mathrm{i}} \\
(\mathrm{mm})\end{array}$ & $\begin{array}{l}\omega_{\mathrm{i}} \\
(\mathrm{mm})\end{array}$ & $\bar{\lambda}$ & $\begin{array}{l}N_{\mathrm{u}} \\
(\mathrm{kN})\end{array}$ \\
\hline \multirow{8}{*}{ S460 SHS $50 \times 50 \times 5$} & C1L1 & 427.0 & 50.33 & 50.32 & 4.98 & 2.02 & 0.42 & 0.36 & 427 \\
\hline & C1L2 & 668.5 & 50.23 & 50.36 & 4.69 & 2.31 & 0.70 & 0.57 & 396 \\
\hline & C1L3 & 907.0 & 50.48 & 50.44 & 4.95 & 2.05 & 0.93 & 0.77 & 384 \\
\hline & C1L4 & 1220.0 & 50.26 & 50.36 & 4.63 & 2.37 & 1.16 & 1.03 & 282 \\
\hline & C1L5 & 1529.0 & 50.43 & 50.43 & 4.89 & 2.11 & 1.45 & 1.30 & 217 \\
\hline & C1L6 & 1700.0 & 50.37 & 50.52 & 5.01 & 2.00 & 1.75 & 1.44 & 182 \\
\hline & C1L7 & 1859.0 & 50.32 & 50.32 & 5.05 & 1.95 & 1.86 & 1.58 & 151 \\
\hline & C1L8 & 2150.0 & 50.37 & 50.39 & 4.92 & 2.08 & 2.21 & 1.83 & 126 \\
\hline \multirow{8}{*}{ S460 SHS $70 \times 70 \times 6.3$} & C2L1 & 649.5 & 70.00 & 69.96 & 6.22 & 3.78 & 0.64 & 0.40 & 792 \\
\hline & C2L2 & 939.0 & 69.90 & 69.95 & 6.29 & 3.72 & 0.94 & 0.59 & 762 \\
\hline & C2L3 & 1280.0 & 69.99 & 69.97 & 6.37 & 3.63 & 1.17 & 0.80 & 651 \\
\hline & C2L4 & 1710.0 & 69.83 & 69.91 & 6.32 & 3.68 & 1.80 & 1.07 & 531 \\
\hline & C2L5 & 2150.0 & 69.96 & 70.06 & 6.32 & 3.69 & 2.34 & 1.34 & 367 \\
\hline & C2L6 & 2400.0 & 69.95 & 70.02 & 6.21 & 3.79 & 2.53 & 1.49 & 309 \\
\hline & C2L7 & 2600.0 & 69.95 & 70.07 & 6.17 & 4.34 & 2.67 & 1.62 & 264 \\
\hline & C2L8 & 3020.0 & 70.00 & 70.02 & 6.37 & 3.63 & 3.08 & 1.88 & 208 \\
\hline \multirow{3}{*}{ S460 SHS $100 \times 100 \times 5$} & C3L1 & 858.3 & 99.69 & 99.28 & 5.19 & 5.81 & 0.91 & 0.35 & 878 \\
\hline & C3L2 & 1759.0 & 99.82 & 99.28 & 5.31 & 5.69 & 1.73 & 0.72 & 798 \\
\hline & C3L3 & 2949.0 & 99.37 & 99.82 & 5.23 & 5.00 & 2.24 & 1.22 & 557 \\
\hline \multirow{8}{*}{ S690 SHS $50 \times 50 \times 5$} & C4L1 & 426.0 & 50.47 & 50.44 & 4.99 & 2.02 & 0.48 & 0.44 & 690 \\
\hline & C4L2 & 668.5 & 50.47 & 50.47 & 4.76 & 2.24 & 0.71 & 0.69 & 637 \\
\hline & C4L3 & 905.5 & 50.45 & 50.43 & 4.82 & 2.18 & 0.93 & 0.94 & 562 \\
\hline & C4L4 & 1220.0 & 50.67 & 50.51 & 4.79 & 2.21 & 1.18 & 1.26 & 391 \\
\hline & C4L5 & 1529.0 & 50.40 & 50.40 & 4.79 & 2.21 & 1.60 & 1.59 & 248 \\
\hline & C4L6 & 1700.0 & 50.60 & 50.40 & 4.95 & 2.05 & 1.72 & 1.76 & 201 \\
\hline & C4L7 & 1860.0 & 50.53 & 50.48 & 4.93 & 2.07 & 1.77 & 1.93 & 166 \\
\hline & C4L8 & 2150.0 & 50.60 & 50.52 & 4.84 & 2.16 & 2.04 & 2.22 & 119 \\
\hline \multirow{3}{*}{ S690 SHS $100 \times 100 \times 5.6$} & C5L1 & 858.0 & 100.43 & 100.53 & 5.67 & 5.33 & 1.03 & 0.44 & 1571 \\
\hline & C5L2 & 1760.0 & 100.50 & 100.52 & 5.72 & 4.78 & 1.66 & 0.89 & 1420 \\
\hline & C5L3 & 2950.0 & 100.70 & 100.59 & 5.78 & 6.22 & 3.00 & 1.50 & 680 \\
\hline
\end{tabular}


TABLE 4: Comparison of column test results with FE results

\begin{tabular}{|c|c|c|c|c|c|c|}
\hline \multirow[b]{2}{*}{ Cross-section } & \multirow[b]{2}{*}{ Label } & \multirow[b]{2}{*}{$\begin{array}{l}N_{\mathrm{u}, \text { test }} \\
(\mathrm{kN})\end{array}$} & \multicolumn{2}{|c|}{ With redisual stresses } & \multicolumn{2}{|c|}{ Without residual stresses } \\
\hline & & & $\begin{array}{l}N_{\mathrm{u}, \mathrm{FE}} \\
(\mathrm{kN})\end{array}$ & $N_{\mathrm{u}, \mathrm{FE}} / N_{\mathrm{u}, \mathrm{test}}$ & $\begin{array}{l}N_{\mathrm{u}, \mathrm{FE}} \\
(\mathrm{kN})\end{array}$ & $N_{\mathrm{u}, \mathrm{FE}} / N_{\mathrm{u}, \mathrm{est}}$ \\
\hline \multirow{8}{*}{ S460 SHS $50 \times 50 \times 5$} & C1L1 & 427 & 427 & 1.00 & 427 & 1.00 \\
\hline & C1L2 & 396 & 391 & 0.99 & 391 & 0.99 \\
\hline & C1L3 & 384 & 388 & 1.01 & 388 & 1.01 \\
\hline & C1L4 & 282 & 298 & 1.06 & 300 & 1.07 \\
\hline & C1L5 & 217 & 226 & 1.04 & 226 & 1.04 \\
\hline & C1L6 & 182 & 189 & 1.04 & 190 & 1.04 \\
\hline & C1L7 & 151 & 161 & 1.06 & 161 & 1.06 \\
\hline & C1L8 & 126 & 121 & 0.96 & 121 & 0.96 \\
\hline \multirow{8}{*}{ S460 SHS $70 \times 70 \times 6.3$} & C2L1 & 792 & 781 & 0.99 & 782 & 0.99 \\
\hline & C2L2 & 762 & 767 & 1.01 & 767 & 1.01 \\
\hline & C2L3 & 651 & 739 & 1.14 & 741 & 1.14 \\
\hline & C2L4 & 531 & 564 & 1.06 & 567 & 1.07 \\
\hline & C2L5 & 367 & 396 & 1.08 & 401 & 1.09 \\
\hline & C2L6 & 309 & 323 & 1.05 & 323 & 1.05 \\
\hline & C2L7 & 264 & 278 & 1.06 & 279 & 1.06 \\
\hline & C2L8 & 208 & 217 & 1.04 & 217 & 1.05 \\
\hline \multirow{3}{*}{ S460 SHS $100 \times 100 \times 5$} & C3L1 & 878 & 939 & 1.07 & 939 & 1.07 \\
\hline & C3L2 & 798 & 896 & 1.12 & 893 & 1.12 \\
\hline & C3L3 & 557 & 581 & 1.04 & 584 & 1.05 \\
\hline \multirow{8}{*}{ S690 SHS $50 \times 50 \times 5$} & C4L1 & 690 & 642 & 0.93 & 643 & 0.93 \\
\hline & $\mathrm{C} 4 \mathrm{~L} 2$ & 637 & 584 & 0.92 & 589 & 0.92 \\
\hline & C4L3 & 562 & 523 & 0.93 & 523 & 0.93 \\
\hline & C4L4 & 391 & 357 & 0.91 & 357 & 0.91 \\
\hline & C4L5 & 248 & 234 & 0.94 & 234 & 0.95 \\
\hline & C4L6 & 201 & 198 & 0.99 & 198 & 0.99 \\
\hline & C4L7 & 166 & 166 & 1.00 & 166 & 1.00 \\
\hline & C4L8 & 119 & 125 & 1.05 & 125 & 1.05 \\
\hline \multirow{3}{*}{ S690 SHS $100 \times 100 \times 5.6$} & C5L1 & 1571 & 1576 & 1.00 & 1571 & 1.00 \\
\hline & C5L2 & 1420 & 1402 & 0.99 & 1407 & 0.99 \\
\hline & C5L3 & 680 & 676 & 0.99 & 676 & 0.99 \\
\hline Mean & & & & 1.015 & & 1.017 \\
\hline $\mathrm{COV}$ & & & & 0.055 & & 0.055 \\
\hline
\end{tabular}


TABLE 5: Summary of statistical parameters for the Eurocode reliability analysis

\begin{tabular}{lllllll}
\hline Dataset & $n$ & $k_{\mathrm{d}, \mathrm{n}}$ & $b$ & $V_{\delta}$ & $V_{\mathrm{r}}$ & $\gamma_{\mathrm{M} 1}$ \\
\hline S460 test & 19 & 3.70 & 0.967 & 0.038 & 0.060 & 1.16 \\
S460 test+FE & 91 & 3.20 & 1.017 & 0.025 & 0.063 & 1.12 \\
S690 test & 11 & 4.33 & 1.053 & 0.054 & 0.070 & 1.14 \\
S690 test+FE & 83 & 3.21 & 1.032 & 0.027 & 0.065 & 1.11 \\
\hline
\end{tabular}

TABLE 6: Summary of statistical parameters for the AISC reliability analysis

\begin{tabular}{llllll}
\hline Dataset & $n$ & $V_{\mathrm{Q}}$ & $V_{\mathrm{R}}$ & $\phi_{\mathrm{c}}$ & $\beta$ \\
\hline S460 test & 19 & 0.19 & 0.060 & 0.9 & 2.58 \\
S460 test+FE & 91 & 0.19 & 0.063 & 0.9 & 2.76 \\
S690 test & 11 & 0.19 & 0.070 & 0.9 & 3.09 \\
S690 test+FE & 83 & 0.19 & 0.065 & 0.9 & 3.02 \\
\hline
\end{tabular}




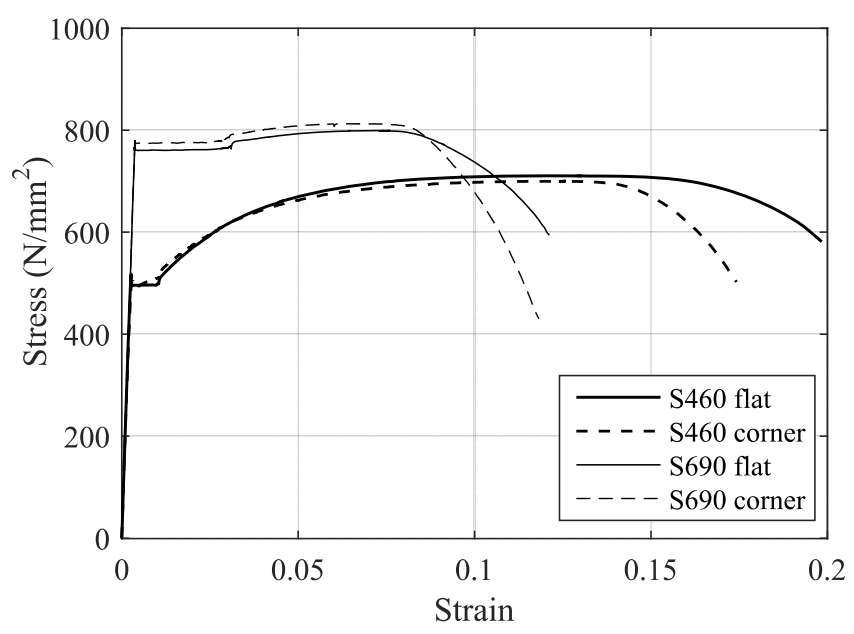

FIG. 1: Typical measured stress-strain curves of S460 and S690 flat and corner coupons

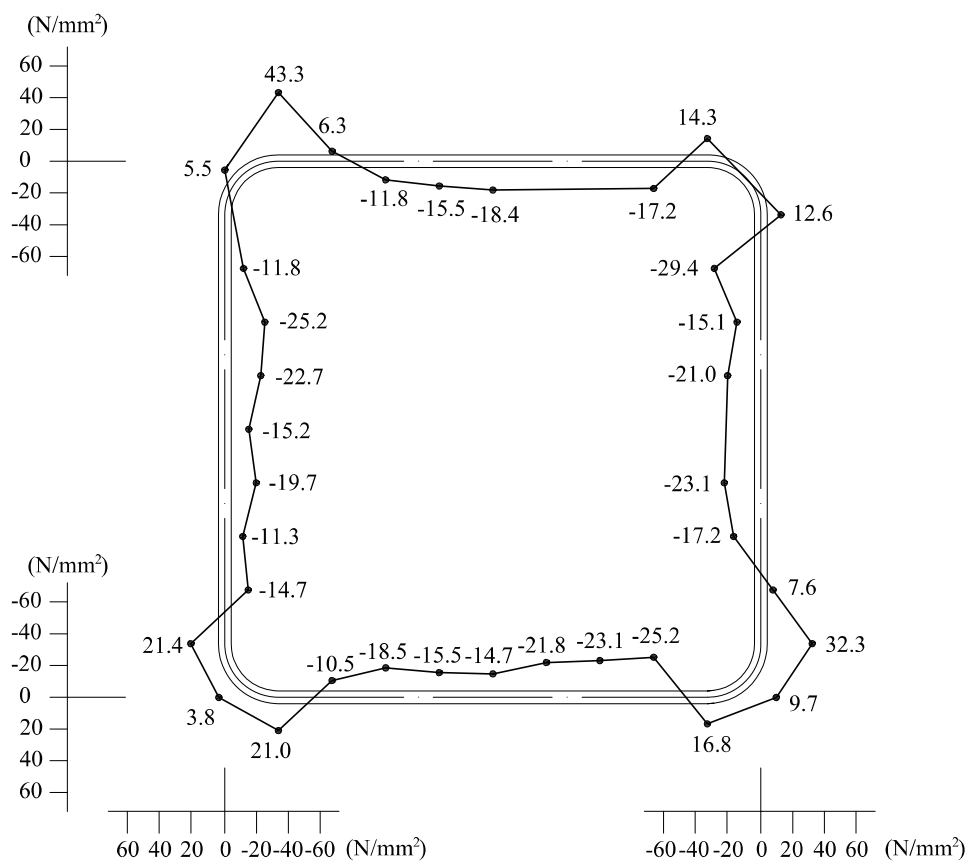

FIG. 2: Measured residual stress distribution in S690 SHS $90 \times 90 \times 5.6$. Residual stresses are shown in $\mathrm{N} / \mathrm{mm}^{2}$, with positive values being tensile and negative values compressive 


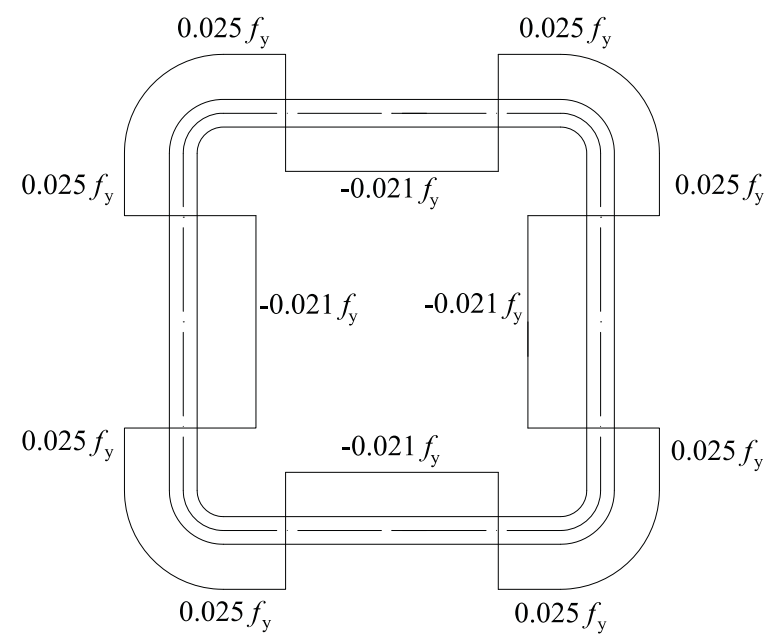

FIG. 3: Residual stress distribution incorporated into FE models.

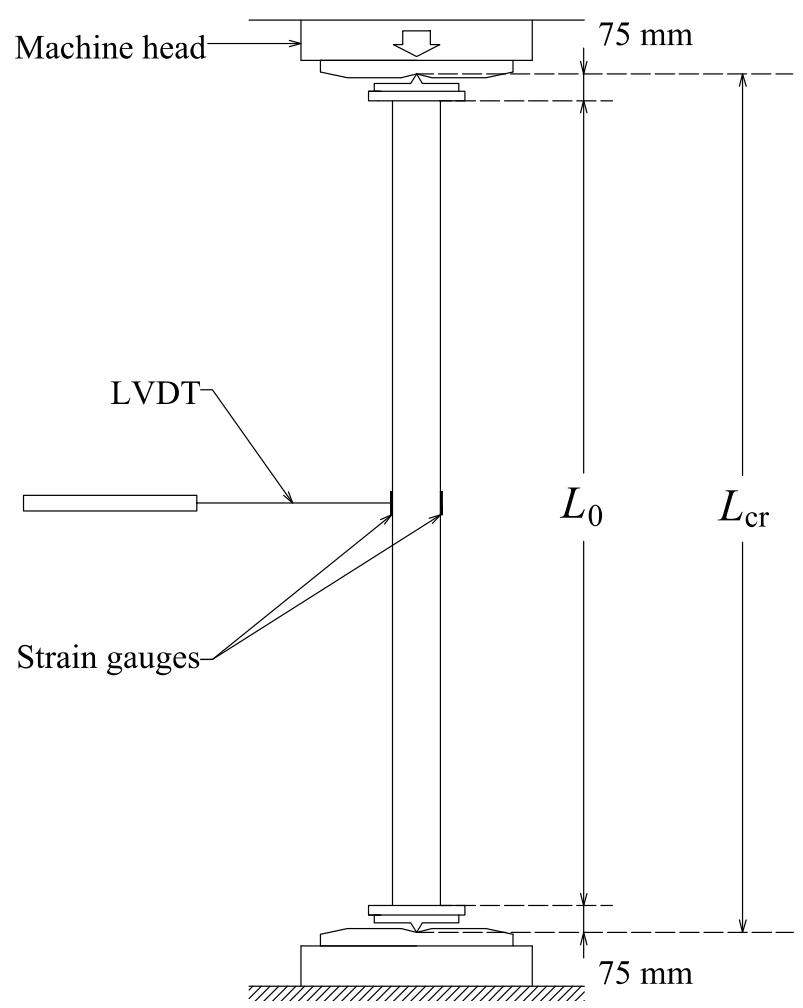

FIG. 4: Column test setup. 


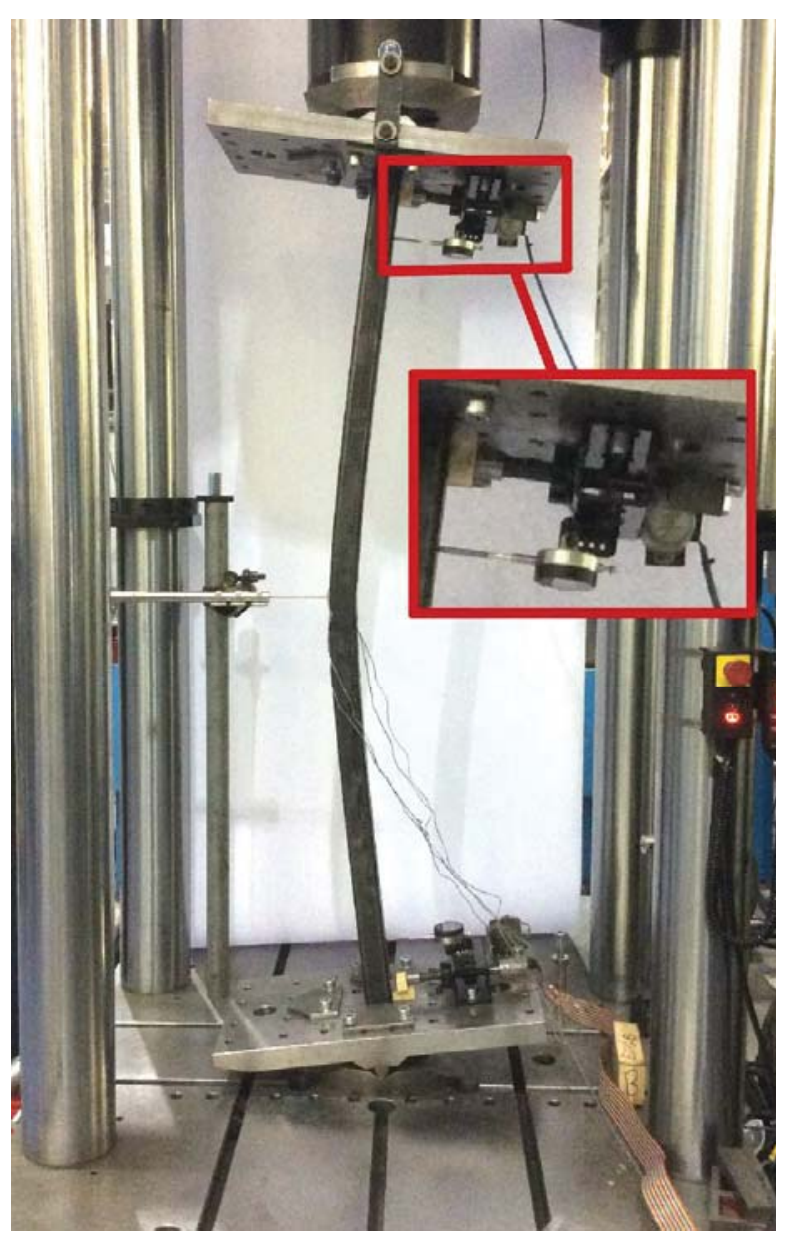

FIG. 5: Photo of column test setup and typical failure mode of specimen

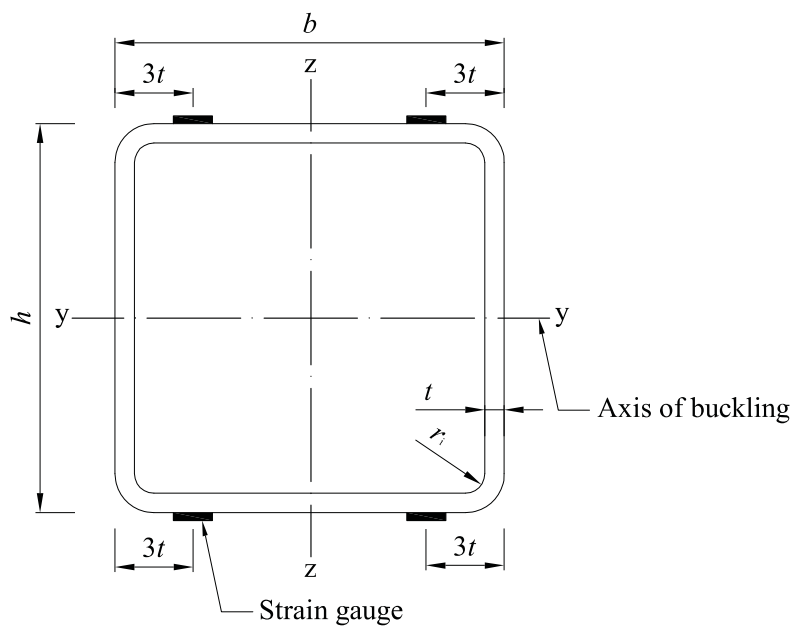

FIG. 6: Geometry of tested cross-sections and locations of strain gauges 


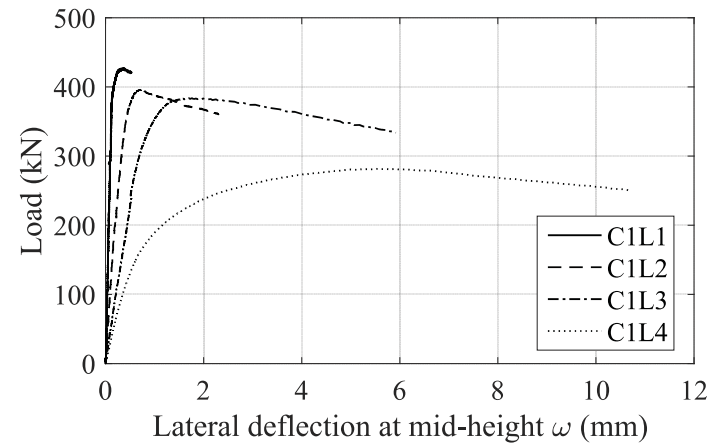

(a) C1L1-C1L4 specimens

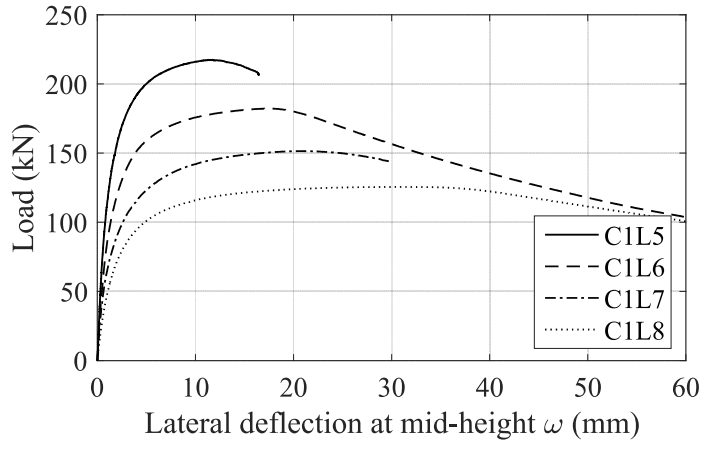

(b) C1L5-C1L8 specimens

FIG. 7: Load-lateral displacement curves of C1 (S460 SHS $50 \times 50 \times 5)$ specimens

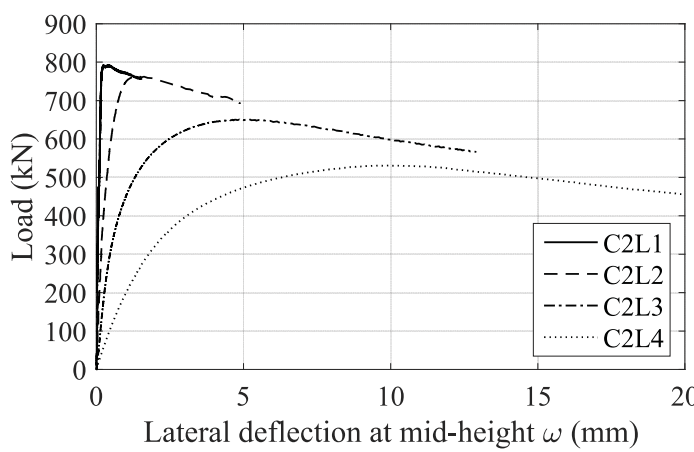

(a) C2L1-C2L4 specimens

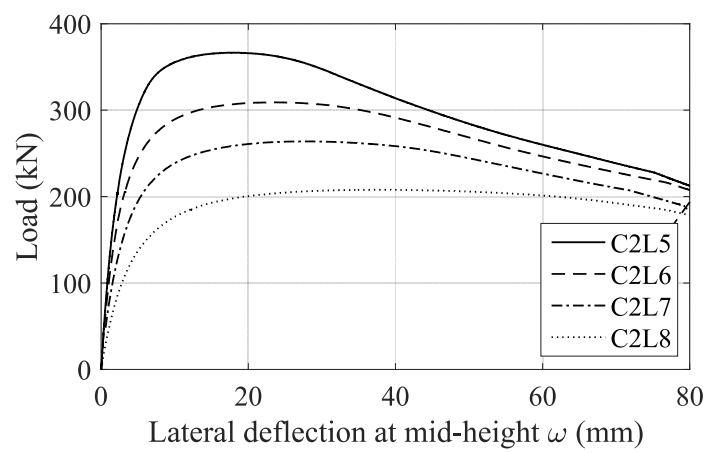

(b) C2L5-C2L8 specimens

FIG. 8: Load-lateral displacement curves of C2 (S460 SHS $70 \times 70 \times 6.3)$ specimens

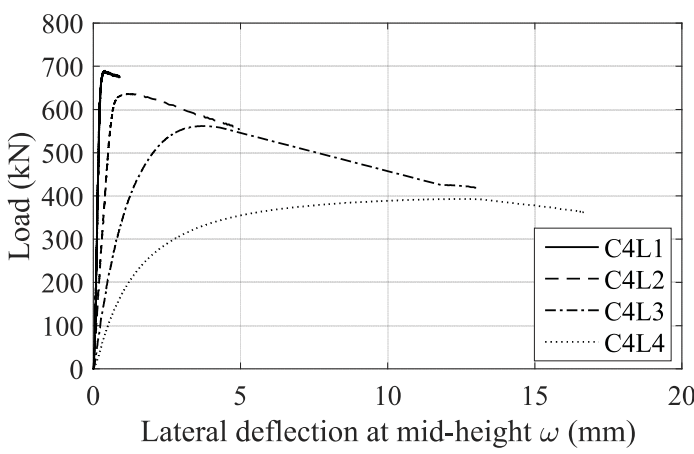

(a) C4L1-C4L4 specimens

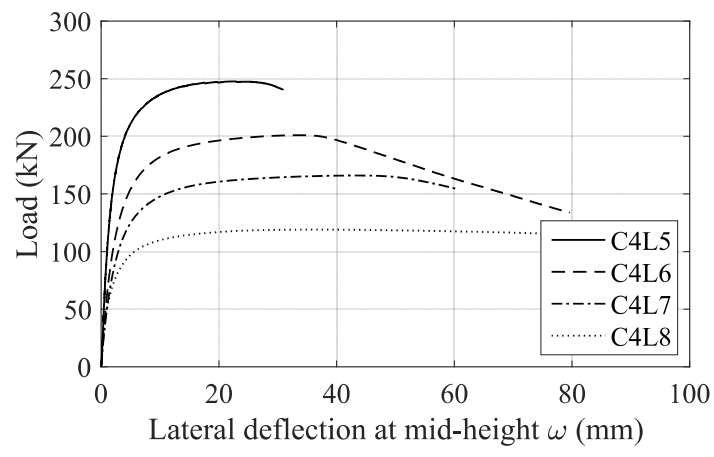

(b) C4L5-C4L8 specimens

FIG. 9: Load-lateral displacement curves of C4 (S690 SHS $50 \times 50 \times 5)$ specimens 


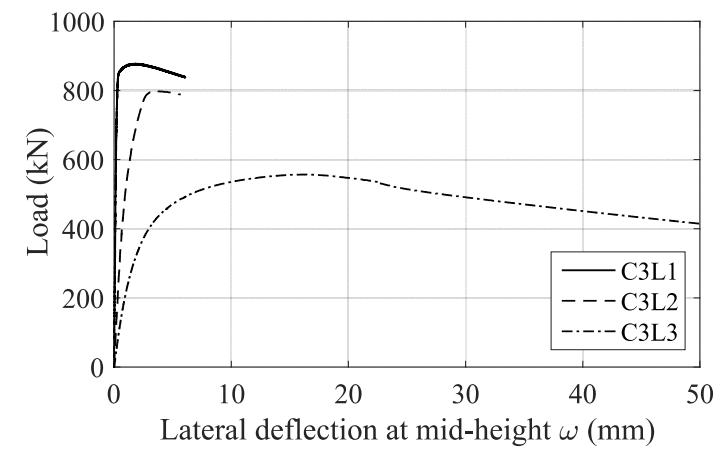

(a) C3L1-C3L3 specimens

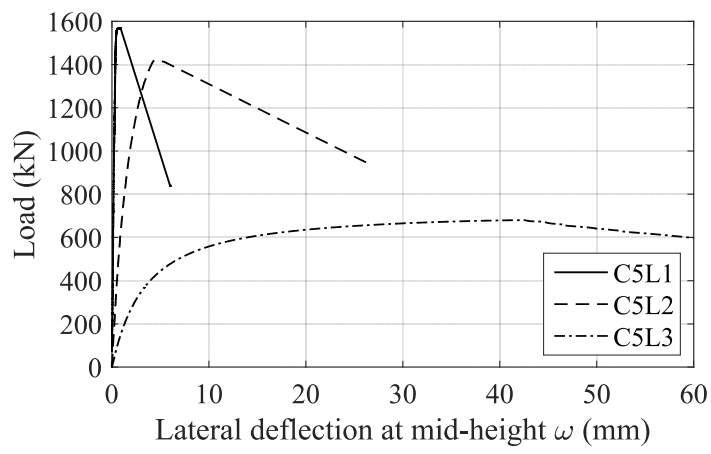

(b) C5L1-C5L3 specimens

FIG. 10: Load-lateral displacement curves of a) C3 (S460 SHS $100 \times 100 \times 5)$ and b) C5 (S690 SHS $100 \times 100 \times 5.6)$ specimens

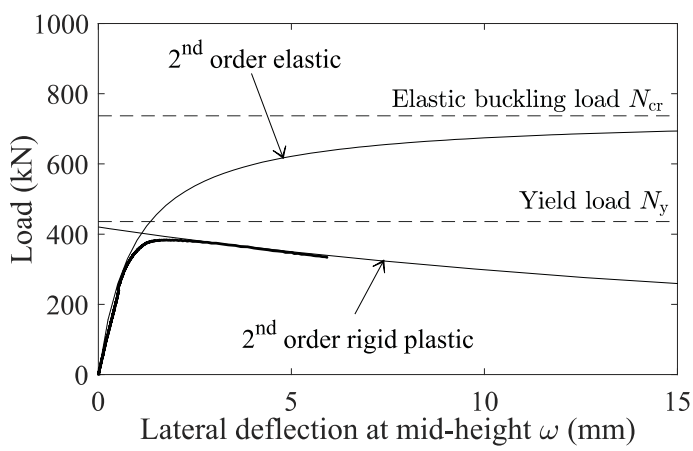

(a) C1L3 specimen

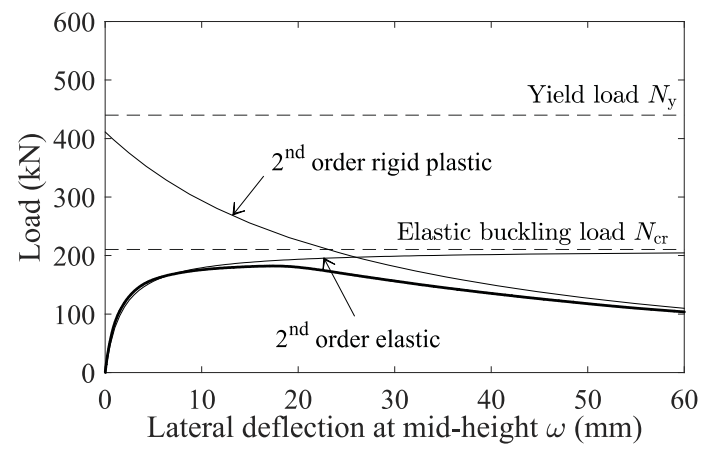

(b) C1L6 specimen

FIG. 11: Load-lateral displacement curves of a) C1L3 and b) C1L6 specimens and comparison with theoretical predictions

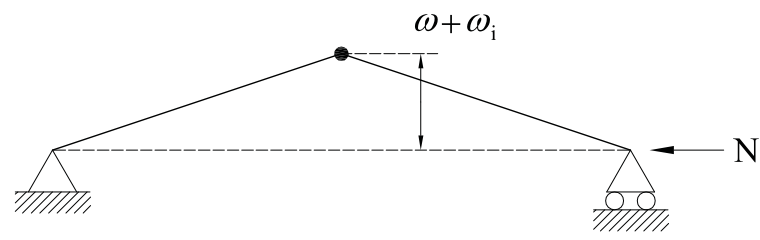

FIG. 12: Second order rigid plastic model 


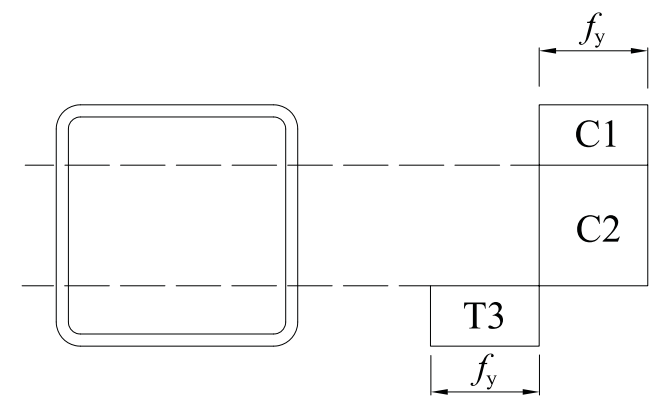

FIG. 13: Assumed plastic stress distribution

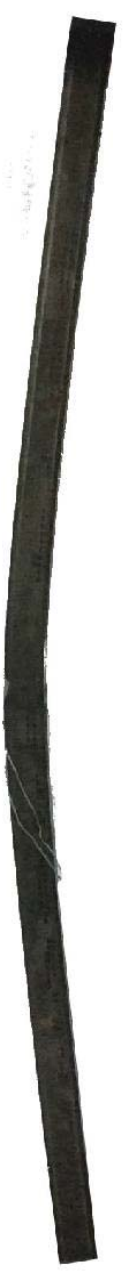

(a) Experiment

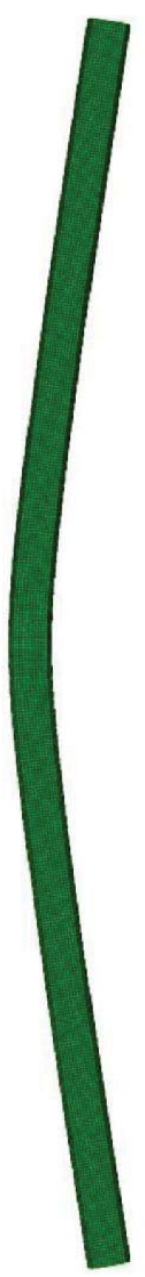

(b) FE model

FIG. 14: Comparison of the failure modes in tested specimen and numerical model (C1L5 member) 


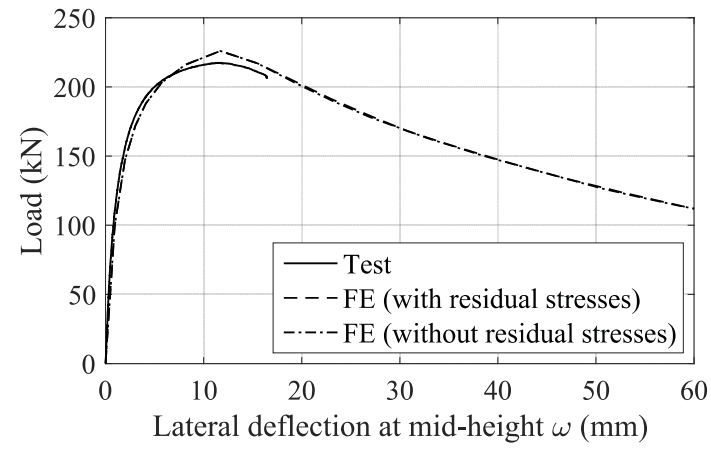

(a) C1L5 member

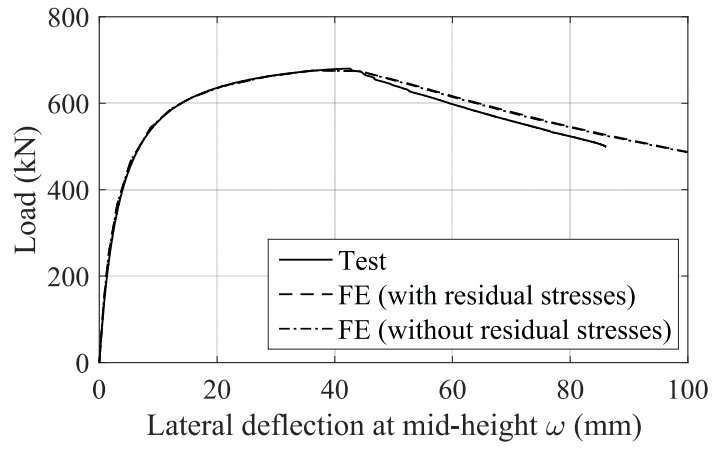

(b) C5L3 member

FIG. 15: Comparison between the load-lateral displacement curves obtained from the test and FE models of a) C1L5 and b) C5L3 member

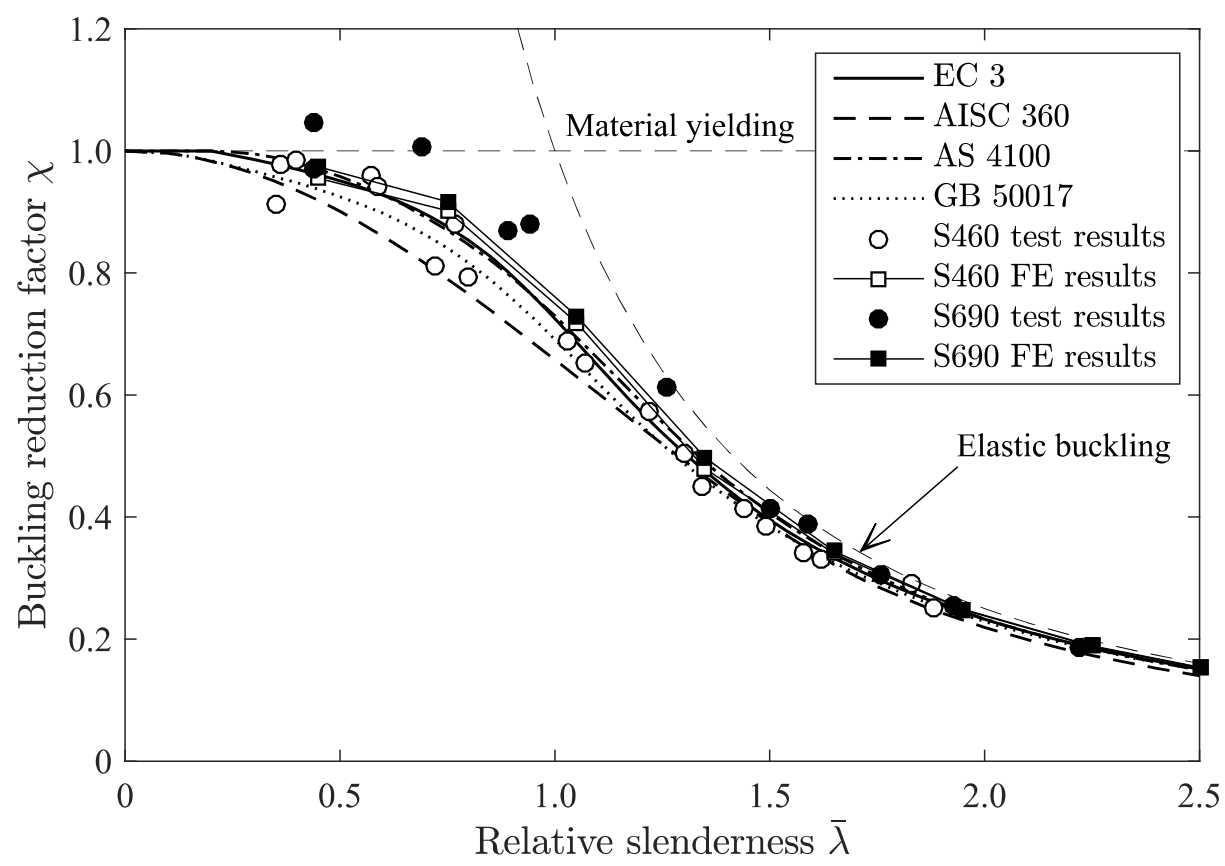

FIG. 16: Normalized test and FE results with nominal column buckling curves 


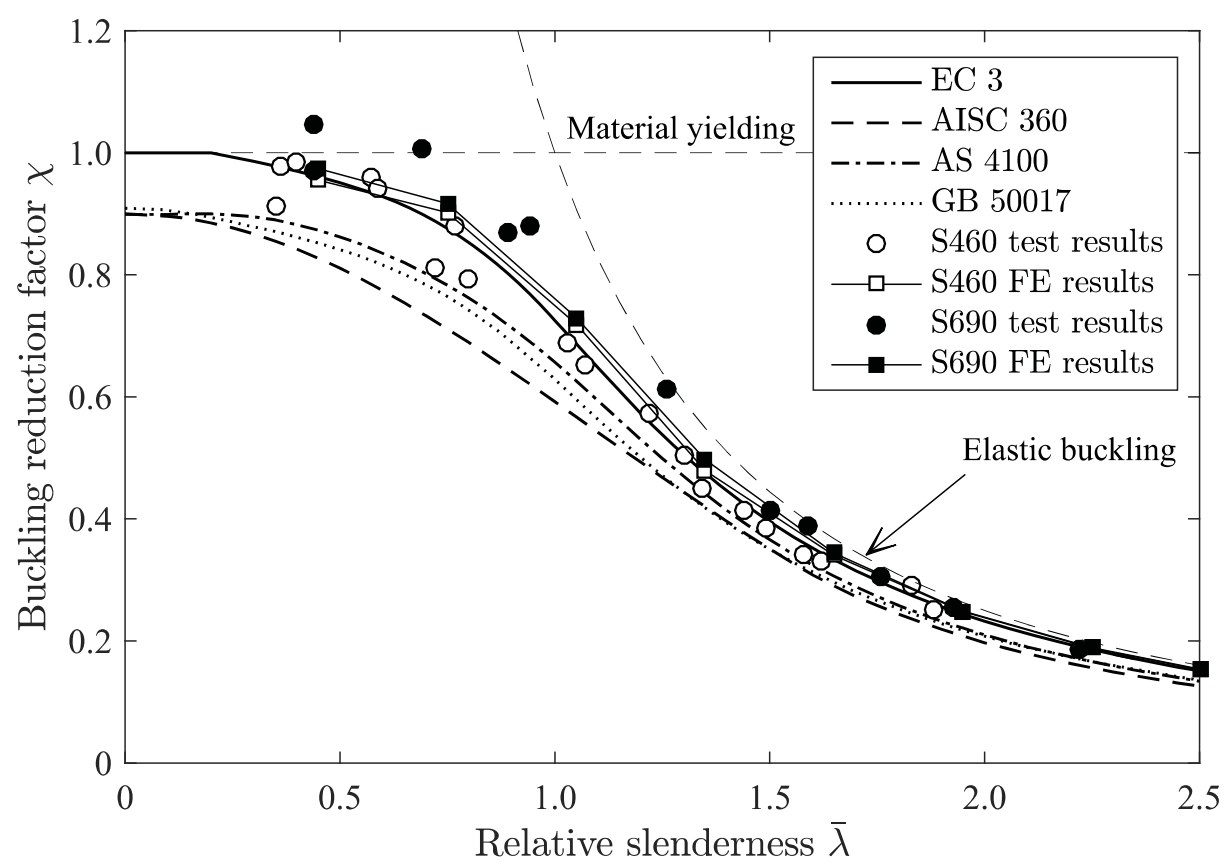

FIG. 17: Normalized test and FE results with design column buckling curves 